\title{
Collaboration FMADM And K-Means Clustering To Determine The Activity Proposal In Operational Management Activity
}

\author{
Rolly Maulana Awanggaa, Syafrial Fachri Pane, Khaera Tunnisa \\ Applied Bachelor Program of Informatics Engineering, Politeknik Pos Indonesia, \\ Jl. Sariasih No 54 Bandung, Bandung, 40151, Indonesia. \\ Tel: (022) - 2009562, Fax: 022 - 2011099 \\ Email: awangga@poltekpos.ac.id
}

\begin{abstract}
Indonesian government agencies under the Ministry of Energy and Mineral Resources still use manual methods in determining and selecting proposals for operational activities to be carried out. This study uses the Decision Support System (DSS) method, namely Fuzzy Multiple Attribute Decision Decision (Fmadm) and K-Means Clustering method in managing Operational Plan activities. Fmadm to select the best alternative from a number of alternatives, alternatives from this study proposed activity proposals, then ranking to determine the optimal alternative. The K-Means Clustering Method to obtain cluster values for alternatives on the criteria for activity dates, types of activities, and activity ceilings. The last iteration of the Euclidian distance calculation data on k-means shows that alternatives that have the smallest centroid value are important proposal criteria and the largest centroid value is an insignificant proposal criteria. The results of the collaboration of the Fmadm and KMeans Clustering methods show the optimal ranking of activities (proposal activities) and the centroid value of each alternative.
\end{abstract}

Keywords: Activity proposal, Operational management of activities, Fmadm, K-means clustering.

\section{INTRODUCTION}

The research and development center for mineral and coal technology (Puslitbang tekMIRA) is an Indonesian government agency under the Ministry of Energy and Mineral Resources. Pusltibang tekMIRA conducts research and development, engineering and design in the field of mineral processing and utilization technology and coal. In realizing it is required the existence of budget management activities. However, the management of the research budget of Puslitbang tekMIRA has problems in determining the activities to be received. There is an employee proposal proposing an activity that has a filing date and a realization date simultaneously. This makes managers difficulty in determining the activities to be accepted. 
Management of Operational Plans of Research activities tekMIRA still uses manual way in determining the activities that will be accepted. Proposal submission of this activity is used by employees Puslitbang tekMIRA to propose activities to be implemented for the next year. The process of submission is the employee make an activity proposal consisting of the name of the activity, the date of the realization of the activity, as well as the amount of activity budget proposed. The subsequent process of proposing the submission of employees will then be assessed and determined by the assessment team. The importance of using efficient means in the assessment, to reduce the occurrence of cheating and misunderstanding [1]. In this assessment, the team assesses by date of activity, whether the date can be carried out the activity. Moreover, also the type of activity, whether the activity is significant to be realized by looking at the benefits of the activity and the output of what is generated from the activity and the next is the amount of budget ceiling proposed activities. The proposed budget must be assessed again to adjust to the type of activity. In this budget appraisal process, the budget of activities to be received can be less than the ceiling or more than the ceiling, by the assessment of the assessment team. However, in the process of evaluating proposals, this activity still uses manual methods. Therefore, inside this study, the researcher applied the FMADM method in assessing proposed activities. FMADM chosen because it was able to select the best alternative from a number of alternatives and research was conducted by looking for weight values for each attribute, then a ranking process will be determined an optimal alternative. The K-Means Clustering method for grouping alternatives based on similar characteristics and to obtain cluster values for alternatives on criteria for activity dates, types of activities, and ceiling activities. This KMeans calculation is divided into several iterations. The last iteration of the data calculates the Euclidian distance on k-means designating an alternative that has a middle value composing an important proposal and the largest centroid value determines the proposal is not important.

Based on the above problems, in this study, researchers applied the FMADM method to facilitate the approval of activity proposals and to select the best proposals from proposal contributions and K-Means Clustering to group activity proposals looking for average price references with the centroid. Implementation of these two methods also helps planning operational activities to be more efficient in assessing activities, selecting proposals to be received and also helping in determining alternative groups (activity proposals) that are important and not important.

\section{RELATED WORKS}

In the previous study, the FMADM method was used for use in the field of financial investment evaluation [2], and attribute decision-making methods to find the optimal parking space in the [3] parking lot, and also used for the interest of high school students [4]. RFID application on WMS to handle the goods selection process [5]. Also, using this method, in retrospect to track the accuracy of the tracking result [6]. In this study, researchers also applied the 
method of clustering K-Means in determining the group. The K-Means algorithm is used for categories of students with skills such as cognitive, communication and relational [7], to evaluate student achievement levels for course content [8], and to group data based on user information created on the SNS and recommend to future users [9]. Grouping data based on user sentences by utilizing the regularity between data pursued by the user using the K-Means Algorithm [10]. The genetic algorithm and K-Means are used to calculate centroid with heterogeneous populations that lead to better results than using random numbers [11]. Clustering is an effort to classify similar objects in the same groups. Cluster analysis constructs good cluster when the members of a cluster have a high degree of similarity to each other (internal homogeneity) and are not like members of other clusters (external homogeneity)[12].

\section{ORIGINALITY}

The research and development center for mineral and coal technology (Puslitbang tekMIRA) is an Indonesian government agency under the Ministry of Energy and Mineral Resources. Pusltibang tekMIRA conducts research and development, engineering and design in the field of mineral processing and utilization technology and coal. In realizing it is required the existence of budget management activities. However, the management of the research budget of Puslitbang tekMIRA has problems in determining the activities to be received. There is an employee proposal proposing an activity that has a filing date and a realization date simultaneously. This makes managers difficulty in determining the activities to be accepted.

Management of Operational Plans of Research activities tekMIRA still uses manual way in determining the activities that will be accepted. Proposal submission of this activity is used by employees Puslitbang tekMIRA to propose activities to be implemented for the next year. The process of submission is the employee make an activity proposal consisting of the name of the activity, the date of the realization of the activity, as well as the amount of activity budget proposed. The subsequent process of proposing the submission of employees will then be assessed and determined by the assessment team. The importance of using efficient means in the assessment, to reduce the occurrence of cheating and misunderstanding [1].

From the background of this research, it is expected to provide a new approach to the problem of submitting activity proposals. The approach is to make an assessment system for activity proposals using the FMADM method and the results of the assessment are then grouped according to groups of important and unimportant proposals using the K-Means Clustering algorithm. In previous studies related to the application of the FMADM method in the assessment using the weights determined by FMADM. In this study the research criteria are based on Filing Schedule, Activities, Number of proposals. The result of applying the FMADM method is the values of each proposal that has been submitted. and the result of the application of the K-Means Clustering method is a group of important and unimportant proposals. 


\section{ADOPTED PREVIOUS METHOD}

\subsection{DSS}

Decision Support System (DSS) is system-specific information intended to assist management in decision-making about semi-structured questions and does not replace decision-making functions in making informed decisions. Decision support systems combine individual intellectual resources with the ability of computers to improve the quality of decisions [13].

\subsection{FMADM}

Fuzzy Multi-Attribute Decision is a method for finding the optimal alternative from some alternatives to a particular criterion [14]. FMADM is the core of determining the weight value for each attribute and the ranking of the process that will select the given alternatives. There are three approaches to finding attribute weights, namely subjective and objective approaches and an integrated approach between subjective and objective. Each approach has its advantages and disadvantages. In a subjective approach, weights are determined based on the subjectivity of the decision maker so some factors in the alternative rank can be determined independently. While the objective approach, the weighting calculation is mathematically ignoring the subjectivity of the decision maker [15].

$$
\begin{aligned}
& \text { To calculate the benefit attribute, use the formula as in Equation[16]. } \\
& \frac{\mathrm{X}_{\mathrm{ij}}}{\operatorname{Max}_{\mathrm{i}} \mathrm{X}_{\mathrm{ij}}} \quad \text { If } \mathrm{J} \text { is a profit attribute }
\end{aligned}
$$

To calculate the cost attribute, using the formula as follows Equation[16].

$$
\frac{X_{i j}}{\operatorname{Max}_{i} X_{i j}} \quad \text { If } J \text { is a profit attribute }
$$

The FMADM algorithm is as follows: [16]

1) Provide the value of each alternative $\left(A_{1}\right)$ on any predefined criteria $(\mathrm{Cj})$, where the value is obtained based on crisp value; $i=1,2, \ldots \mathrm{m}, \mathrm{j}=1,2, \ldots$ n. $(\mathrm{Cj})\left(C_{j}\right)(\mathrm{Cj})$

2) Provide weight value (W) which is also obtained based on crisp value.

3) Normalize the matrix by calculating the normalized performance rating value of the other attribute based on the equation that is adjusted to the type of attribute according to the following equation

4) Perform the ranking process by multiplying the normalized matrix $(R)$ with the weight value $(W)$

Rank $=\mathrm{R} \times \mathrm{W}$

5) Specifies the preference value for each alternative (Vi) by summing the product of the normalized matrix (R) with the weight value (W). A larger Vi value indicates that alternative $(\mathrm{Ai})$ is more elected.Preference value $\left(V_{i}\right)=$ $\left(R_{1}+W_{1}\right)+\left(R_{2}+W_{2}\right)+\left(R_{n}+W_{n}\right)$ 


\subsection{K-Means}

The definition of K-Means Clustering is, $\mathrm{K}$ is a constant of the number of clusters expected. Means, in this case, means an average value of a data group which in this case is called a cluster [11]. K-Means Clustering is a data analysis method or data mining method that performs an unsupervised modeling process and is a method of grouping data with a partition system. The K-Means method tries to classify existing data into several groups, where data in one group has the same characteristics with each other and has different characteristics from the data that is in another group [17].

The steps of clustering with the K-Means method are as follows: [18]. (a). Select the number of clusters k. (b). Initializing the cluster center k can be done in various ways. However, the most often done is by random. Cluster centers are given an initial value with random numbers, (c). Allocate all data/objects to the nearest cluster. The proximity of two objects is determined based on the distance between the two objects. Likewise, the proximity of a data to a particular cluster is determined by the distance between the data and the cluster center. In this stage, it is necessary to calculate the distance of each data to each cluster center. The most distance between one data with one particular cluster will determine which data entered in the cluster. To count the distance of all data to each cluster center, you can use the Euclidean Distance theory which is formulated as follows:

K-means algorithm formula $\mathrm{d}=$ distance, $\mathrm{j}=$ amount of data, $\mathrm{c}=$ centroid, $\mathrm{x}=$ data, $\mathrm{c}=$ centroid. Euclidean distance equation.

$\mathrm{D}(\mathrm{i}, \mathrm{j})=$
$\sqrt{\left(\mathrm{X}_{1 \mathrm{i}}-\mathrm{X}_{1 \mathrm{j}}\right)^{2}+\left(\mathrm{X}_{2 \mathrm{i}}-\mathrm{X}_{2 \mathrm{j}}\right)^{2}+\ldots+\left(\mathrm{X}_{\mathrm{ki}}-\mathrm{X}_{\mathrm{kj}}\right)^{2}}$

Information : $\mathrm{D}(\mathrm{i}, \mathrm{j})$ is the distance of data between $\mathrm{i}$ and center cluster $\mathrm{j}$. $\mathrm{Xki}$ is the data to $\mathrm{i}$ on attribute data to $\mathrm{k}$. $\mathrm{X}\{\{\mathrm{kj}\}\}$ is the center point to $\mathrm{j}$ at attribute to $\mathrm{k}$.

(d). Recalculate the cluster center with Current membership cluster. Center Clusters are the average of all data / in the cluster and also use the median of the cluster. So it is average (on average) not the only size that can be used.

(e). Assign each object again to use the new cluster center. If it is central the cluster does not change again then the process clustering is complete. Alternatively, go back to step number 3 to the center of the cluster does not change again. 


\section{EXPERIMENT AND ANALYSIS}

\subsection{Experiment}

\subsubsection{FMADM}

In this study, researchers used the method FMADM. Fuzzy MADM is a method to find the optimal alternative of some alternatives with specific criteria. The alternative mentioned in this research is the employee who submitted the proposed activity budget plan at Puslitbang tekMIRA. Implementation of FMADM logic on the Rating System for submission of activity budget plan with the following steps

Alternative design (Ai) on each criterion (Cj). The criteria specified in the assessment of prospective proposals for the development budget of TekMIRA research activities are Filing Schedule, Number of proposals, Activities. In Table 1 the assessments have unrelated taste criteria The value entered on the criteria are: 10 is perfect, 9 is the Very Good, 8 is the Good 7 is the Enough and 6 is the Less. And if converted to fuzzy number it will be like the following figure: fuzzy numbers can be converted to crisp number: Less $=0$; Enough = $0.25 ;$ Good $=0.50$; Very good $=0.75$; and Perfect $=1$.

Table 1. Fuzzy Rating Assessment Criteria

\begin{tabular}{|c|c|}
\hline Rating Result & Value \\
\hline 6 & 0 \\
\hline 7 & 0.25 \\
\hline 8 & 0.5 \\
\hline 9 & 0.75 \\
\hline 10 & 1 \\
\hline
\end{tabular}

Gives a weight value (W) which is also obtained based on crisp value. The weighting of criteria (W) based on the importance of the assessment is: $0=$ Very Low (VL), 1 = Low (L), 3 = Enough (E), 4 = Height (H), 5 = Very High ( VH ). And if converted to fuzzy number it will be fuzzy numbers can be converted to crisp number: $\mathrm{VL}=0 ; \mathrm{L}=0.25 ; \mathrm{E}=0.50 ; \mathrm{H}=0.75$; and $\mathrm{VH}=1$; Moreover, the decision-maker gives the following values. In Table 2 is the assessment criteria in the proposed proposal of activity budget details at TekMIRA Research Center. There are three criteria along with the weight of the assessment.

Table 2. Fuzzy Rating Assessment Criteria

\begin{tabular}{|c|c|}
\hline Criteria & Weight \\
\hline Filing Schedule & 0.75 \\
\hline Activities & 0.50 \\
\hline Number of proposals & 1 \\
\hline
\end{tabular}

Assessment criteria and weights for (Filing schedule) C1. if ( $<1$ month) $=1,(\geq 1$ month $)=0.75,(=2$ month $)=0.50$, and $(\leq 2$ month $)=0.25$. Assessment 
criteria and weights for (Number of proposals) C2. If $(<P a g u)=1,(=$ Pagu $)=0.75$ and $(>$ Pagu $)=0$. And also Assessment criteria and weights for (Activities) C3. If (Very important $)=1$, (Important $)=0.75$ and (Not important) $=0.25$.

Assessment results in eight candidates who submitted activity proposals in operational management activities and applied FMADM logic for assessment of activity schedule, activity type, and activity budget. Results of Alternative Assessment for each criterion C1 Schedule of Activities, C2 Number of Proposals and C3 Proposed Status in Table 3.

Table 3. Table Assessment Filing schedule, Number of proposals

\begin{tabular}{|c|c|c|c|c|c|c|c|c|}
\hline Criteria & A1 & A2 & A3 & A4 & A5 & A6 & A7 & A8 \\
\hline C1 & 9 & 7 & 9 & 8 & 8 & 9 & 7 & 6 \\
\hline C2 & 9 & 9 & 10 & 6 & 10 & 10 & 8 & 7 \\
\hline C3 & 9 & 10 & 7 & 7 & 10 & 8 & 8 & 9 \\
\hline
\end{tabular}

- Fuzzy Value for Filing Schedule, Number of proposals, Activities in Table 4

Table 4. Fuzzy Value for Filing Schedule, Number of proposals, Activities

\begin{tabular}{|c|c|c|c|}
\hline Alternatif & C1 & C2 & C3 \\
\hline A1 & 0.75 & 0.75 & 0.75 \\
\hline A2 & 0.25 & 0.75 & 1 \\
\hline A3 & 0.75 & 1 & 0.25 \\
\hline A4 & 0.50 & 0 & 0.25 \\
\hline A5 & 0.5 & 1 & 1 \\
\hline A6 & 0.75 & 1 & 0.5 \\
\hline A7 & 0.25 & 0.5 & 0.5 \\
\hline A8 & 0 & 0.25 & 0.75 \\
\hline
\end{tabular}

- Normalization of the matrix of the formula in the equation.

The scoring of each alternative on each criterion is a matching value; then all criteria are valued as an attribute of profit. Criteria C1 For Alternative A1 $\{0.75,0.25,0.75,0.50\}$

$$
\frac{0.75}{\max 0.75,0.25,0.75,0.50}=\frac{0.75}{0.75}=1
$$

Moreover, so do the calculations for $\mathrm{A} 1$ for $\mathrm{C} 2, \mathrm{C} 3$ and continue the calculations for A2, A3, and A4, A5, A6, A7, A8 by the calculation. Table 5 is the result of the calculation for the next candidate. 
Table 5. Normalization matrix Filing schedule, Number of proposals, Activities

\begin{tabular}{|c|c|c|c|}
\hline Alternatif & C1 & C2 & C3 \\
\hline $\mathrm{A} 1$ & 1 & 0.75 & 0.75 \\
\hline $\mathrm{A} 2$ & 0.33 & 0.75 & 1 \\
\hline $\mathrm{A} 3$ & 1 & 1 & 0.25 \\
\hline $\mathrm{A} 4$ & 0.67 & 0 & 0.25 \\
\hline $\mathrm{A} 5$ & 0.66 & 1 & 1 \\
\hline $\mathrm{A} 6$ & 1 & 1 & 0.5 \\
\hline $\mathrm{A} 7$ & 0.33 & 0.5 & 0.5 \\
\hline $\mathrm{A} 8$ & 0 & 0.25 & 0.75 \\
\hline
\end{tabular}

\subsubsection{K-Means Clustering Method}

Table 6, the last iteration of the Euclidian distance calculation data on k-means. Criterion C1 is Schedule Activity (A), C2 is the Number of Proposals (B), and C3 are Proposed Status (C). Calculation of K-Means it is divided into 2 centroids, the centroid is divided and the biggest is the data. Results of This last iteration calculation is an alternative that has the highest value of centroid. Grouping values using the k-Means algorithm collects into two groups, which have centroid values important appraisal proposal and biggest proposal centroid value not important. In the last iteration, alternative data does not move anymore so it can be ascertained Calculations have been completed and alternative groups that have the highest value of assessment and have found. Result (C1) and Result (C2) is the average value of the calculation results divided into 2 centroids, namely the largest and the smallest.

Table 6. Comparison of result values from $\mathrm{C} 1(\mathrm{C})$ and $\mathrm{C} 2(\mathrm{~W})$ (Iteration 3)

\begin{tabular}{|c|c|c|c|c|c|c|c|c|c|c|c|c|}
\hline $\mathbf{A}$ & B & C & C1(A) & C1(B) & C1(C) & C2(A) & C2(B) & C3(C) & RESULT(C1) & RESULT(C2) & C1 & $\mathrm{C} 2$ \\
\hline 0.75 & 0.75 & 0.375 & 0.4973 & 1.5833 & 0.4167 & 1.0583 & 0.5 & 0.2083 & 0.871771 & 0.430509 & & 1 \\
\hline 0.247 & 0.75 & 0.5 & 0.4973 & 1.5833 & 0.4167 & 1.0583 & 0.5 & 0.2083 & 0.874058 & 0.897662 & 1 & \\
\hline 0.75 & 0.75 & 0.125 & 0.4973 & 1.5833 & 0.4167 & 1.0583 & 0.5 & 0.2083 & 0.918333 & 0.405571 & & 1 \\
\hline 1.675 & 0 & 0.125 & 0.4973 & 1.5833 & 0.4167 & 1.0583 & 0.5 & 0.2083 & 1.994719 & 0.798284 & & 1 \\
\hline 0.495 & 2 & 0.50 & 0.4973 & 1.5833 & 0.4167 & 1.0583 & 0.5 & 0.2083 & 0.424951 & 1.628618 & 1 & \\
\hline 0.75 & 2 & 0.25 & 0.4973 & 1.5833 & 0.4167 & 1.0583 & 0.5 & 0.2083 & 0.515058 & 1.531923 & 1 & \\
\hline 0.247 & 0.5 & 0.25 & 0.4973 & 1.5833 & 0.4167 & 1.0583 & 0.5 & 0.2083 & 1.124268 & 0.81231 & & 1 \\
\hline 0.75 & 0.75 & 0.375 & 0.4973 & 1.5833 & 0.4167 & 1.0583 & 0.5 & 0.2083 & 1.384958 & 0.43059 & & 1 \\
\hline
\end{tabular}

\subsection{Result}

The grouping results using k-means grouping and there are two groupings in Table 7. Group 1 for alternatives (activity proposal) which has the smallest centroid value for the criteria important for grouping 2 for alternatives (activity proposals) which are the largest centroid values for 
criteria are not important. Proposals with important categories are A2, A5, A6, while the categories are not important are A1, A3, A4, A7, A8.

Table 7. The final result of the assessment

\begin{tabular}{|c|c|c|}
\hline Alternative & Important & $\begin{array}{c}\text { Not } \\
\text { Important }\end{array}$ \\
\hline A1 & & 1 \\
\hline A2 & 1 & \\
\hline A3 & & 1 \\
\hline A4 & & 1 \\
\hline A4 & 1 & \\
\hline A6 & 1 & \\
\hline A7 & & 1 \\
\hline A8 & & 1 \\
\hline
\end{tabular}

\section{CONCLUSION}

By applying the FMADM method, in this case, the requested alternative is an activity proposal based on specified criteria. The study was conducted for the weight values for each attribute, then ranking is done which will determine the optimal alternative, namely the activity proposal. ranking results alternatives and then alternatives are grouped using the K-Means Clustering method to find out Alternative groups based on the same criteria. Calculation results using Euclidian distance at k-means that it is divided into 2 centroids which are limited centroids and the largest centroids. Criteria for This grouping is an alternative (activity proposal) that has a value of centroid value important activity proposals and those that have the greatest centroid value are not important. Collaboration between the two methods has made it easier for the TekMIRA Research Center for activity proposals will be accepted and later activities. Important activities (proposals) are A2, A5, A6. Alternative (proposal for non-essential activities are A1, A3, A4, A7, A8. Thus, proposals with groups This importance is determined to be received and implemented first because of an alternative (proposal Activities) have high valuation values and assessment requirements for rating ratings.

\section{Acknowledgments}

First, you should acknowledge any significant technical help that you received from any individual, whether in your laboratory or elsewhere. You should also acknowledge the source of special equipment, cultures, or other materials. Second, it is usually the acknowledgments wherein you should acknowledge any outside financial assistance, such as grants, contracts or fellowships. 


\section{REFERENCES}

[1] H. A. Nugroho, T. Pinandita, Sistem Penilaian Proposal Penelitian Dosen Universitas Muhammadiyah Purwokerto Berbasis Web Service dengan Android, JUITA: Jurnal Informatika 2 (3).

[2] Z.-Y. Lv, L.-W. Zheng, X.-N. Liang, X.-Z. Liang, A fuzzy multiple attribute decision making method based on possibility degree, Journal of Intelligent \& Fuzzy Systems 31 (2) (2016) 787-794.

[3] S. Yu, B. Li, Q. Zhang, M. Q.-H. Meng, An optimal parking space search model based on fuzzy multiple attribute decision making, in: Intelligent Control and Automation (WCICA), 2012 10th World Congress on, 2012, pp. $4350-4355$.

[4] F. N. Khasanah, A. E. Permanasari, S. SuningKusumawardani, Fuzzy MADM for major selection at senior high school, in: Information Technology, Computer, and Electrical Engineering (ICITACEE), 2015 2nd International Conference on, 2015, pp. 41-45.

[5] S. F. Pane, R. M. Awangga, B. R. Azhari, Qualitative Evaluation of RFID Implementationon Warehouse Management System, TELKOMNIKA (Telecommunication Computing Electronics and Control) 16 (3).

[6] R. M. Awangga, N. S. Fathonah, T. I. Hasanudin, Colenak: GPS tracking model for post-stroke rehabilitation program using AES-CBC URL encryption and QR-Code, in: 2017 2nd International conferences on Information Technology, Information Systems and Electrical Engineering (ICITISEE), IEEE, 2017, pp. 255-260. URL 10.1109 /ICITISEE. 2017.8285506

[7] J. Yi, S. Li, M. Wu, H. A. Yeung, W. W. Fok, Y. Wang, F. Liu, Cloud-based educational big data application of apriori algorithm and k-means clustering algorithm based on students' information, in: Big Data and Cloud Computing (BdCloud), 2014 IEEE Fourth International Conference on, 2014, pp. 151-158.

[8] L. Guoli, W. Tingting, Y. Limei, L. Yanping, G. Jinqiao, The improved research on k-means clustering algorithm in initial values, in: Mechatronic Sciences, Electric Engineering and Computer (MEC), Proceedings 2013 International Conference on, 2013, pp. 2124-2127.

[9] S.-H. Jung, J.-C. Kim, C.-B. Sim, Prediction data processing scheme using an artificial neural network and data clustering for Big Data, International Journal of Electrical and Computer Engineering 6 (1) (2016) 330.

[10] A. Bedboudi, C. Bouras, M. T. Kimour, An Heterogeneous PopulationBased Genetic Algorithm for Data Clustering, Indonesian Journal of Electrical Engineering and Informatics (IJEEI) 5 (3) (2017) 275-284.

[11] Q. Shi, L. Xu, Z. Shi, Y. Chen, Y. Shao, Analysis and research of the campus network user's behavior based on k-means clustering algorithm, in: Digital Manufacturing and Automation (ICDMA), 2013 Fourth International Conference on, 2013, pp. 196-201. 
[12] Barakbah, Ali Ridho, and Kohei Arai, Centronit: Initial Centroid Designation Algorithm for K-Means Clustering, EMITTER International journal of engineering technology 2.1 (2014): 50-62.

[13] S. Narabin, V. Boonjing, Selecting students to a dormitory using AHP, in: Computer Science and Software Engineering (JCSSE), 2016 13th International Joint Conference on, 2016, pp. $1-5$.

[14] M. Mansouri, C. Leghris, The use of MADM methods in the vertical handover decision making context, in: Wireless Networks and Mobile Communications (WINCOM), 2017 International Conference on, 2017, pp. $1-6$.

[15] S.-M. Chen, J.-A. Hong, Fuzzy multiple attributes group decisionmaking based on ranking interval type- 2 fuzzy sets and the TOPSIS method, IEEE Transactions on Systems, Man, and Cybernetics: Systems 44 (12) (2014) 1665-1673.

[16] S. Kusumadewi, S. Hartati, A. Harjoko, R. Wardoyo, Fuzzy MultiAttribute Decision Making (Fuzzy MADM), Yogyakarta: Graha Ilmu.

[17] J. MacQueen, et al., Some methods for classification and analysis of multivariate observations, in: Proceedings of the fifth Berkeley symposium on mathematical statistics and probability, Vol. 1, 1967, pp. 281-297.

[18] Z. Gheid, Y. Challal, Efficient and Privacy-Preserving k-Means Clustering for Big Data Mining, in: Trustcom/BigDataSE/I SPA, 2016 IEEE, 2016, pp. 791-798. 